\title{
De "corpos" a "pessoas": a atuação das pacientes através do julgamento da Dra. Mary Dixon Jones de 1892*
}

\author{
Regina Morantz-Sanchez ${ }^{* *}$
}

\begin{abstract}
Resumo
Este artigo discute o sensacional processo de 1892 entre o jornal Eagle, Do Brooklin, Nova Iorque, e uma conhecida cirurgiã ginecologista, Dra. Mary Amanda Dixon Jones. Sugiro que o evento confirmou e ajudou a mudar a compreensão sobre o corpo feminino $e$ as doenças ginecológicas para as pacientes, os espectadores do julgamento e o público mais amplo. O desenvolvimento da cirurgia ginecológica alterou as relações entre médico e paciente, permitindo que mulheres pobres e de classe média falassem no tribunal sobre sua penosa experiência da doença. O julgamento proporcionou um canal público incomum para a divulgação das reclamações quanto à condição feminina, assim como para discussão sobre a prática médica.
\end{abstract}

Palavras-chave: Ginecologia, Corpo Feminino, Doença, Gênero, Atuação.

* Tradução de Daniela Araújo, Revisão: Heloisa Buarque de Almeida, Elizabeth Juliska Rago e Mariana Meloni Vieira Botti. Recebido para publicação em janeiro de 2004, aceito em setembro de 2004.

** Universidade de Michigan, Michigan, Estados Unidos. reginann@umich.edu 
De "corpos" a "pessoas"

From "Bodies" to "Persons": Female Patient Agency

as Revealed in the 1892 Trial of Dr. Mary Dixon Jones

\begin{abstract}
This article examines a sensational public libel trial that took place in 1892 between the Brooklyn, New York, Eagle newspaper and a well-known female gynecological surgeon, Dr. Mary Amanda Dixon Jones. I suggest that the event both affirmed and helped authorized changing understandings of women's bodies and gynecological disease for female patients, trial spectators, and the larger public. It suggests that the development of gynecological surgery altered doctor-patient relationships which enabled middle class and even some poor women to speak in the courtroom about the burdensome experience of illness. The trial provided an unusual public venue for airing disappointments and complaints about the female condition, as well as the discussion about medical practices.
\end{abstract}

Key words: Gynecology, Female Body, Sickness, Gender, Agency. 
Em fevereiro e março de 1892, um sensacional julgamento de um processo por difamação colocou o Eagle, o maior jornal do Brooklyn, Nova Iorque, contra a Dra. Mary Amanda Dixon Jones, uma cirurgiã ginecologista cuja reputação não era desprezível. Estavam em questão várias reportagens terríveis publicadas no jornal, na primavera de 1889 , sobre a prática médica de Dixon Jones. Começando por notar a deliberada má administração financeira de seu hospital, o Woman's Hospital of Brooklyn, o Eagle seguiu retratando Dixon Jones como uma alpinista social calculista e ambiciosa, uma cirurgiã "amiga da faca" $e$ irresponsável, que submetia mulheres inocentes a cirurgias desnecessárias e utilizava os fragmentos delas extraídos para melhorar sua reputação em diagnóstico e patologia. Os jornalistas tomaram a história com entusiasmo. No Brooklyn, os artigos sobre Dixon Jones desencadearam publicamente uma avalanche de críticas contra ela, dando origem a duas acusações de homicídio culposo e oito processos de má conduta profissional que chegaram aos tribunais. Foram necessários quase dois anos para que Dixon Jones limpasse seu nome de todas as acusações civis $e$ criminais; e quando sua provação terminou, ela retaliou com um processo contra o Eagle, exigindo 300 mil dólares por danos.

O julgamento que se seguiu foi um evento público notável, o mais longo processo por difamação julgado nos Estados Unidos até então. Quase 300 testemunhas depuseram, incluindo médicos renomados, humildes artesãos e costureiras, imigrantes que falavam apenas um inglês precário, comerciantes com suas esposas e antigas pacientes com bebês nos braços. Os espectadores lotavam o tribunal dia após dia, fixando a atenção na exibição de manequins cirúrgicos e ovários preservados em frascos, que se tornaram, da noite para o dia, visões comuns no tribunal. A linguagem técnica da prática cirúrgica e da anormalidade celular expôs os observadores a uma nova linguagem profissional e a novas formas de compreender o corpo humano. Os jornais Citizen e Times do Brooklyn, New York Times, e World de Nova Iorque mantinham os leitores informados 
De "corpos" a "pessoas"

com tom dramático. O Brooklyn Medical Journal alegava que o evento envolvia a "honra e reputação" do seu estabelecimento médico, enquanto o Philadelphia Ledger aclamava o caso como "o mais importante (...) desde o escândalo Beecher", uma referência ao julgamento de adultério escandaloso que colocou o marido de uma mulher, membro de uma congregação evangélica, contra um pastor evangélico bastante popular do Brooklyn no início da década de 1870.

Noutra oportunidade, argumentei que o caso de Dixon Jones ilumina um complexo conjunto de desdobramentos culturais e sociais do final do século XIX. Ele representa um capítulo na história social da medicina que confirma a centralidade de questões médicas na vida cultural norte-americana do período - exemplifica o surgimento de novos modelos de especialização médica, de identidade profissional e de relações entre médicos e pacientes. As tensões de classe e as crescentes mazelas urbanas também conformaram as questões diariamente tratadas no tribunal. Aspectos de gênero moldaram estes outros fenômenos em articulações sutis e específicas, medindo os sucessos e fracassos das médicas e possibilitando discussões francas $e$ abertas sobre saúde feminina em canais surpreendentemente públicos. ${ }^{1}$

A controvérsia centrava-se na enigmática figura da Dra. Mary Dixon Jones. Uma mulher visivelmente ambiciosa que, quer de forma deliberada ou não intencional, ignorou os scripts de gênero que ditavam a conduta profissional adequada para as médicas de seu tempo; e foi devidamente punida por seus esforços. Ela perdeu tudo quando um júri masculino considerou o Eagle inocente da acusação de difamação em 1892. A campanha do jornal a destituiu de apoios influentes no Brooklyn e a licença de seu hospital foi revogada. Derrotada, abandonou a prática

\footnotetext{
1 Para uma análise mais detalhada do significado deste evento ver MORANTZSANCHEZ, Regina. Conduct Unbecoming a Woman: Medicine on Trial in Turn of the Century Brooklyn. New York, Oxford University Press, 1999.
} 
médica e mudou-se para a cidade de Nova York, embora tenha continuado a publicar sobre patologia ginecológica. $\mathrm{O}$ exílio do Brooklyn marcou não apenas sua exclusão de uma carreira médica bem-sucedida, dolorosamente construída durante 30 anos, mas também da prática cirúrgica e do aprimoramento de novas técnicas de operação que ela própria havia contribuído para criar. Para quem lutou por um lugar na história, talvez a mais triste decepção tenha sido a resultante exclusão de sua carreira do registro histórico.

Mary Dixon Jones foi humilhada em 1892, em parte porque era mulher, mas mais provavelmente porque era uma mulher que insistiu em praticar cirurgia ginecológica radical. Contudo, antes de concluirmos que o julgamento representa apenas outra história monótona do poder profissional masculino e da vulnerabilidade das médicas do sexo feminino, eu gostaria de propor uma leitura mais complexa desse evento, ao sugerir que nem todas as mulheres perderam quando Dixon Jones perdeu seu processo. ${ }^{2}$

2 A discriminação de gênero vivenciada por Dixon Jones era complexa e contraditória. Embora ao final do século as mulheres houvessem feito grandes incursões na medicina, esperava-se que se comportassem de maneira feminina, com deferência a seus colegas masculinos, e que se comportassem junto aos pacientes de maneira mais acolhedora e compassiva, mesmo quando empregavam as mesmas modalidades de tratamento. O estilo de Dixon Jones não era de coleguismo ou de deferência, e isso exasperava não apenas os colegas homens, mas também as colegas no Brooklyn. Três médicas do Brooklyn testemunharam contra ela e há evidências de que muitas pensavam que ela não era um bom exemplo de conduta profissional feminina adequada. Embora não fosse a única médica a realizar cirurgia ginecológica $e$ a defender a excisão cirúrgica como o tratamento mais eficaz para a doença pélvica naquela época, o público ainda concebia a cirurgia como uma especialidade "masculina". O comportamento de Dixon Jones no julgamento reforçou a percepção de muitos de que ela não era suficientemente feminina, enquanto seu entusiasmo desenfreado pelo trabalho cirúrgico e pela ciência laboratorial em geral evocava o espectro do "cientista maluco". Médicos podiam manifestar tal interesse abertamente, mas ouvir uma mulher falar sem hesitação sobre ovários doentes e trompas de falópio danificadas aparentemente perturbava muitas pessoas. A relutância de Dixon Jones de desempenhar um papel socialmente prescrito de feminilidade não se perdeu no júri completamente masculino. Aqueles que 
De "corpos" a "pessoas"

Por volta de 1892 , ela própria era uma cirurgiã nacional e internacionalmente conhecida, uma pioneira cujas operações inovadoras e contribuições à patologia celular do sistema reprodutivo feminino eram bem conhecidas por colegas do sexo masculino nos Estados Unidos e no exterior. Ela talvez tenha sido a única médica de sua geração cujos trabalhos publicados se referiam, de modo consistente e por um longo período de tempo, às grandes discussões e debates terapêuticos que ocorriam no campo da cirurgia ginecológica. Ela negociou cuidadosamente para si tal identidade profissional em um tempo em que as fronteiras, condutas e ideologias da prática médica estavam em movimento. Ao final do século, poucas médicas mulheres haviam alcançado tal proeminência.

$\mathrm{O}$ julgamento deu visibilidade pública à carreira de Dixon Jones, a despeito de seu decepcionante resultado. Entretanto, para um maior grupo de mulheres - pacientes reais e potenciais de Dixon Jones - o evento teve um significado mais amplo. O drama eletrizante do tratamento médico, tão abertamente vivido na Suprema Corte do Estado do Brooklyn, abriu espaço para se avaliar a emergente especialidade da cirurgia ginecológica $e$ encarar mulheres e seus corpos sob um novo viés. Basta um passar de olhos em um jornal para recordarmos de que processos legais escandalosos podem imbuir a vida cotidiana de significado dramático. Ao engajar um público mais amplo, eles por vezes

desejarem procurar uma discussão mais elaborada das questões do profissionalismo masculino e feminino e a relação de gênero com o tratamento médico podem consultar MORANTZ-SANCHEZ, Regina. Doctors and Patients Gender and Medical Treatment in Nineteenth-Century América. In: Sympathy and Science: Women Physicians in American Medicine. New York, Oxford University Press, 1985 e Chapel Hill, University of North Carolina Press, 2000; Morantz-SANCHEZ, Regina. Negotiating Power at the Bedside: Nineteenth Century Patients and Their Gynecologists. Feminist Studies, Summer, 2000, e The Gendering of Empathy: Late-Nineteenth Century Medical Practice and Ideas of the Good Physician. In: MorE, Ellen e Mulligan, Maureen. (eds.) The Empathic Practitioner: Essays on Empathy, Gender and Medicine. New Brunswick, Rutgers University Press, 1994. 
conduzem a momentos de transformação cultural e auto-reflexão coletiva. Eu gostaria de sugerir que o caso de difamação de Dixon Jones foi um desses acontecimentos. O que estava sendo julgado era a terapia cirúrgica para mulheres e a linguagem científica precisa da patologia e do procedimento cirúrgico. O tribunal tornou-se um fórum para catalisar e marcar a mudança cultural, enquanto a natureza pública de seus procedimentos permitiu que mulheres comuns - aquelas que participaram do caso, testemunharam, ou apenas leram a respeito - reivindicassem um novo e admirável senso de si mesmas como corpos manipuláveis e como pessoas.

Muitos de nós estamos familiarizados com as principais linhas do discurso médico a respeito das mulheres no mundo anglo-americano do século XIX, mas eu gostaria de revisá-las brevemente aqui. A partir dos anos 1830 até aproximadamente a última década do século XIX, doença e saúde surgiram como preocupações constantes da cultura vitoriana, e uma fé crescente na ciência médica levou muitas pessoas da classe média a procurarem tratamento médico. Mulheres de classe média passaram, com relativa freqüência, a procurar cuidados de saúde para suas famílias, bem como para si mesmas. Elas sofriam de uma variedade de doenças dolorosas e debilitantes, incluindo cistos ovarianos, infecções uterinas, deslocamentos e lacerações após o parto, distúrbios menstruais, sangramentos excessivos ou ausência de menstruação, tumores, fibroses e várias formas de câncer. De fato, suas doenças serviam para confirmar a ênfase dos médicos no aparelho reprodutivo feminino como a força fisiológica dominante de seu ser, uma teoria que ganhava poder discursivo graças a um paradigma biológico emergente que enfatizava a diferença masculino-feminina, que surge, de acordo com Thomas Laqueur, no final do século XVIII. ${ }^{3}$

3 Sobre as teorias emergentes da incomensurabilidade masculino-feminina ver Laqueur, Thomas. Making Sex: Body and Gender from the Greeks to Freud. Cambridge, Mass., Harvard University Press, 1990. Sobre a crescente crença na ciência médica entre mulheres, ver MORANTZ-SANCHEZ, Regina. Making Women 
De "corpos" a "pessoas"

De modo crescente, os médicos encontravam justificativas para afirmar que a reprodução era repleta de risco e a crença na saúde doentia das mulheres era amplamente disseminada. Quando a historiadora Wendy Mitchinson examinou os prontuários de 1892 de pacientes de um hospital canadense para mulheres, ela descobriu que os médicos atribuíam aos órgãos sexuais a causa das doenças mesmo quando os males e os sintomas não possuíam qualquer ligação com eles, por exemplo, quando pacientes apresentavam gastrite ou tuberculose. ${ }^{4}$ Para muitos médicos era evidente que um traço característico significativo de ser mulher no século XIX era o de vivenciar "a patologia da feminilidade". ${ }^{5} \mathrm{O}$ obstetra inglês William Tyler Smith, por exemplo, caracterizava o parto como um evento que estava "na fronteira entre a fisiologia e a patologia". Nenhum distúrbio constitucional severo, concordava o ginecologista americano Dr. Arthur Edis,

pode prolongar-se em uma mulher durante a prevalência da função ovariana sem acarretar perturbação... E o inverso também é verdadeiro: o distúrbio dos órgãos sexuais não pode persistir sem acarretar um distúrbio constitucional, ou afetar nocivamente a condição de outros órgãos. ${ }^{6}$

Modern: Middle-Class Women and Health Reform in the 19th Century. Journal of Social History, n 10, June 1977, pp.490-507.

${ }^{4}$ Mitchinson, Wendy. The Nature of Their Bodies: Women and Their Doctors in Victorian Canada. Toronto, University of Toronto Press, 1991, p.47.

5 Moscucci, Ornella. The Science of Woman: Gynecology and Gender in England, 1820-1929. Cambridge, Cambridge University Press, 1990, p.102.

6 SMITH, W.T. Lectures on parturition, and the principles and practice of obstetricy. Lancet, $\mathrm{n}^{\circ} 2$, 1848, p.119; EDIS, Arthur. Diseases of Women: A Manual for Students and Practitioners. Philadelphia, 1882, p.20; BARNES, Robert. Women, diseases of. In: QuAIN, R. (ed.) A Dictionary of Medicine: Including General Pathology, General Therapeutics, Hygiene, and the Diseases Peculiar to Women and Children. London, 1882, vol.II, p.1790. As citações de Barnes e Smith são mencionadas em MoscuccI, Ornella. The Science of Woman... Op. cit., p.102. 
Regina Morantz-Sanchez

\section{Conforme o cirurgião George Rohé reconhecia,}

Entre o público geral e a profissão médica, a influência de anormalidades de órgãos sexuais na produção de aberrações mentais é [...] reconhecida em um grau considerável. De fato, algumas das mais respeitáveis autoridades em doenças mentais, como Esquirol e Guislain, enfatizaram a influência determinante dos órgãos genitais, sobretudo em mulheres, na produção de insanidade. ${ }^{7}$

Tais exemplos sugerem que os médicos consideravam o corpo feminino mais em abstrato do que em particular. A passividade $e$ a resignação das mulheres frente a ameaçadoras realidades biológicas e ao sofrimento físico freqüente possuíam uma poderosa força discursiva, particularmente durante o desenvolvimento inicial da especialidade da ginecologia, quando os especialistas tinham pouco a oferecer em termos de tratamento. Mesmo a propaganda médica na imprensa popular reforçava essa visão, e há bastante evidência de que as pacientes compartilhavam dela. ${ }^{8}$ Antes da assepsia e sem meio algum para

7 RoHÉ, George H. The Relation of Pelvic Disease and Psychical Disturbance in Women. Transactions of the American Association of Obstetricians and Gynecologists (5), 1892, p.321.

8 Sally Shuttleworth mostrou que anúncios de pílulas femininas supunham "uma continuidade direta entre o funcionamento do ciclo menstrual e a saúde mental". ShUTTLEWORTH, Sally. Female Circulation: Medical Discourse and Popular Advertising in the Mid-Victorian Era. In: JACOBUS, Mary; KELLER, Evelyn Fox; Shuttleworth, Sally. (eds.) Body/Politics: Women and the Discourses of Science. New York, Routledge, 1990, pp.47-68. Andrew Scull e Diane Fabreau demonstram bem tal ponto em "A Chance to Cut is a Chance to Cure": Sexual Surgery for Psychosis in Three Nineteenth-Century Societies. Research in Law, Deviance, and Social Control (8), 1986, p.17. Ver também THERIOT, Nancy. Women's Voice in Nineteenth-Century Medical Discourse: A Step Toward Deconstructing Science. Signs (19), Autumn, 1993, pp.1-31 e suas observações sobre as bases físicas da ideologia do sofrimento do século XIX em Mothers and Daughters in Nineteenth-Century America: The Biosocial Construction of Femininity. Louisville, University Press of Kentucky, 1999, pp.40-61; MORANTZ- 
De "corpos" a "pessoas"

aliviar a dor, os primeiros ginecologistas relutavam em operar mulheres, principalmente mulheres brancas de classe média, consideradas particularmente sensíveis. Até a década de 1870 , quando a cirurgia tornou-se uma opção de tratamento - ainda que bastante arriscada - a maioria dos especialistas oferecia parcos recursos, diagnosticando doenças femininas graves como incuráveis. Limitavam-se a fazer punções e drenagens de cavidades repletas de fluidos, à remoção da hipertorfia dos pequenos lábios e a procedimentos plásticos menores sob a forma de reparos no períneo, curetagens e tratamentos tópicos para uma série de indicações inflamatórias. Drenos esponjosos e pessários inseridos na entrada do cérvix também eram os recursos favoritos para lidar com deslocamentos uterinos.

Os corpos das mulheres permaneceram abstrações para os médicos também em outro sentido. Eles eram usados, conforme Mary Poovey demonstrou, para executar "o trabalho ideológico do gênero". A família burguesa vitoriana naturalizada, com seu modelo de esferas separadas, contribuiu no estabelecimento de uma infinidade de novas instituições e relações sociais, desde elaborar políticas em relação aos pobres, regulamentar a prostituição e repensar a legislação referente ao divórcio, até novas formas de expressão literária e o desenvolvimento da teoria social, política e econômica. Imagens de mulheres sofredoras e virtuosas - sempre concebidas como mães ou mães em potencial - acompanhadas por construções modestas e inofensivas do desejo feminino eram indispensáveis às identidades masculinas

SanchEZ, Regina. Sympathy and Science: Women Physicians in American Medicine. New York, Oxford University Press, 1985, pp.215-216. Também é interessante, em termos de atitudes de pacientes o trabalho de SHORTER, Edward. From Paralysis to Fatigue: A History of Psychosomatic Illness in the Modern Era. New York, Free Press, 1992, capítulos 2 e 3. Ver também Mitchinson, W. The Nature of... Op.cit., p.50, que sugere que a percepção médica da frágil saúde feminina ganhou credibilidade, ao menos em parte, por reforçar o que as pessoas já acreditavam. É claro que as concepções médicas tanto refletiam quanto contribuíam para conformar as idéias a respeito das mulheres. 
capitalistas emergentes, tanto na Inglaterra quanto nos Estados Unidos. A moralidade tornou-se altamente dependente dos novos discursos de gênero baseados na linguagem da domesticidade. A virtude, agora identificada com feminilidade, empatia, altruísmo $e$ benevolência social, estava seguramente instalada no âmbito privado da vida familiar. De acordo com Poovey, a nova moralidade deixava a sociedade vitoriana com a faca e o queijo na mão. Ao ligar o comportamento ético, compreensivo e de autosacrifício à figura da Mulher, "imune ao interesse próprio e à competição inerentes ao sucesso econômico", a virtude podia ser preservada "sem inibir a produtividade". A ordem social $e$ a confiança em uma sociedade humana e estável dependiam da crença em imagens de mulheres maternais, voltadas para o lar, como se estas representassem a realidade. ${ }^{9}$

Essa ideologia associou-se ao discurso médico sobre o corpo feminino para exercer um papel dominante na formação das definições de feminilidade de fins do século XIX, que restringiam as mulheres e limitavam suas oportunidades de várias maneiras. Nancy Theriot e outras demonstraram brilhantemente como a experiência discursiva das mulheres - a prescrição relativa à submissão, auto-sacrifício e sofrimento - foi inscrita no corpo de numerosas formas. Ela argumenta que nos dois primeiros terços do século XIX, mulheres que sofriam as seqüelas do controle da fertilidade, do aborto (que era amplamente disseminado) e do parto aprenderam a aceitar a dor física como um símbolo idealizado de sua superioridade moral $e$ de sua devoção aos demais. ${ }^{10}$

9 Poovey, Mary. Uneven Developments: The Ideological Work of Gender in Mid-Victorian England. Chicago, University of Chicago Press, 1988, p.10. Ver também BLOCH, Ruth. American Feminine Ideals in Transition: The Rise of Moral Motherhood, 1785-1815. Feminist Studies (4), June 1978, pp.101-126. Também auxilia no mapeamento da reconformação da sexualidade feminina nos séculos XVIII e XIX COTT, Nancy. Passionlessness: An Interpretation of Victorian Sexual Ideology. Signs (4), Winter 1978, pp.219-136.

${ }^{10}$ THERIOT, N. Mothers and Daughter... Op.cit., p.65. 
De "corpos" a "pessoas"

Acadêmicos de inúmeras disciplinas contribuíram para este panorama ao descrever um sem-número de procedimentos médicos invasivos (tais como cauterização, sangria $e$ clitoridectomia) de modo bastante incentivador, e ao aplicar essas idéias no tratamento das mulheres. Muitos sublinharam a orgia de cirurgias ginecológicas ocorridas nas duas últimas décadas daquele século, argumentando que tais concepções da biologia feminina sancionavam procedimentos "transgressivos" - operações que punham vidas em risco, e que ofereciam a oportunidade para que os especialistas testassem uma variedade de novas modalidades $e$ técnicas terapêuticas. ${ }^{11}$ Entretanto, historiadores da medicina, particularmente na última década, têm demonstrado como muitas destas alegações foram exageradas, apresentando um retrato demasiadamente simplificado de uma interação mais complexa entre o cuidado com o paciente, a teoria médica, o mercado médico, avanços científicos e tecnológicos e a profissionalização. Eu gostaria de elaborar e ampliar essas críticas a partir das evidências advindas do julgamento de difamação de Mary Dixon Jones.

Eu proponho que o surgimento da ginecologia cirúrgica no último terço do século permitiu que as pacientes desenvolvessem uma nova forma de agenciamento em sua luta contra a doença, $e$ gradualmente lhes possibilitou encarar seus corpos de maneira diferente. Ao final, esta especialidade desafiou os discursos

${ }^{11}$ BARKER-Benfield, G.J. The Horrors of the Half-Known Life: Male Attitudes Toward Women and Sexuality in Nineteenth-Century America. New York, Harper \& Row, 1976; SHOWALTER, Elaine. The Female Malady. New York, Pantheon, 1985; POOVEY, Mary "Scenes of an Indelicate Character": The Medical "Treatment" of Victorian Women. Representations (14), Spring 1986, pp.137168; SEwell, Jane E. Bountiful Bodies: Spencer Wells, Lawson Tait, and the Birth of British Gynaecology. Tese de doutoramento, Johns Hopkins University, 1991, p.290. A palavra "transgressiva" é empregada por Sewell, mas ela é muito mais cuidadosa do que outros autores ao explicar os desenvolvimentos internos na prática médica, para além do desejo de manter as mulheres em seus devidos lugares, que podem ter motivado os médicos a experimentar tais procedimentos. Seu trabalho é complexo e de qualidade. 
médicos e culturais dominantes a respeito do auto-sacrifício e do sofrimento feminino. Inauguraram-se novas representações de mulheres doentes, não apenas como corpos abstratos $e$ construções ideológicas, mas como pessoas com uma maior gama de escolhas ao lidar com a doença. O julgamento de Mary Dixon Jones apresenta ao historiador uma oportunidade de mensurar essa transição e explorar suas conseqüências. A publicidade e a discussão pública que gerou permitiu a asserção $e$ a validação do recém-descoberto agenciamento das mulheres em questões de saúde. O evento pode até ser considerado transformador, não apenas por dar novas perspectivas às mulheres que dele participaram como testemunhas ou observadoras, mas também ao oferecer uma nova imagem das mulheres para o consumo público.

Primeiro, quero tratar de minha afirmação de que a cirurgia ginecológica alterou a natureza do discurso médico a respeito das mulheres. Como um todo, o discurso médico até o final do século XIX exerceu um forte papel na formação das definições de feminilidade que reprimiam as mulheres e limitavam de várias maneiras suas oportunidades. É sabido que foi o corpo feminino que permitiu aos cirurgiões explorar com ousadia a cavidade interna do corpo e experimentar uma série de tratamentos cirúrgicos que contribuíram para a criação da especialidade. Entretanto, houve forças contrárias que também devem ser consideradas. Enquanto foram primordialmente homens que primeiro usaram a linguagem de autoridade da ciência para falar $e$ escrever a respeito dos corpos das mulheres, as carreiras de Mary Dixon Jones e de um punhado de outras médicas proeminentes sugerem que a ausência de vozes de mulheres na prática médica nunca foi tão rigorosa nos Estados Unidos quanto era na Inglaterra ou no continente Europeu. As mulheres realmente aprenderam a falar por si mesmas nos Estados Unidos, primeiro como estudiosas de fisiologia no movimento de reforma da saúde, depois como praticantes sectárias de medicina e, finalmente, na segunda metade do século, como médicas formalmente treinadas 
De "corpos" a "pessoas"

e profissionalmente licenciadas. ${ }^{12}$ As médicas participaram entusiasticamente na expansão do papel dos ginecologistas como monitores da saúde feminina, e auxiliaram na ampliação da autoridade desta especialidade para o público leigo. Há evidências claras de que as médicas tiveram impacto nos pontos de vista de seus colegas especialistas do sexo masculino. Ao final do século, muitos médicos concediam a colegas mulheres uma certa perícia onde a saúde feminina estava envolvida, enquanto outros consideravam necessário citar opiniões de médicas sobre o assunto para sustentar sua própria autoridade..$^{13}$

Além das incursões que as mulheres estavam realizando na profissão, meu exame da literatura médica sobre a saúde feminina dos anos de 1870 ao início do século XX detecta uma interessante mudança de conteúdo e um foco mais estreito. Talvez a mudança possa ser mais bem caracterizada como um afastamento de discussões que utilizavam a biologia para a especulação filosófica sobre os papéis e comportamentos femininos adequados, enquanto se favoreciam cada vez mais de abordagens típicas do olhar mais reducionista da ciência médica. Isso significou a diminuição da atenção no comentário sociológico, enquanto discussões sobre técnica, diagnóstico e tratamento se expandiram. A literatura médica e científica como um todo refletiu essa mudança notável em linguagem e orientação, conforme Nancy Stepan e Sander Gilman demonstraram. O argumento moral e político foi marginalizado conforme a ciência adotou "categorias conceituais, estilos retóricos e metodologias". ${ }^{14}$ Este desenvolvimento foi bem-vindo, e talvez mesmo catalisado, pelos cirurgiões e significava ressaltar tecidos doentes e órgãos inflamados mais do que ponderar sobre o papel social destas partes do corpo.

${ }^{12}$ Morantz-SANCHEZ, Regina. Sympathy and Science... Op.cit.

${ }^{13}$ ID. Conduct Unbecoming... Op. cit., pp.119-126.

${ }^{14}$ StePAn, Nancy e GILman, Sander. Appropriating the Idioms of Science: The Rejection of Scientific Racism. In: LACAPRA, Dominick. (ed.) The Bounds of Race. Ithaca, Cornell University Press, 1991. 
A própria Dixon Jones adotou o uso da patologia e as contribuições que a ciência laboratorial estava fazendo à prática clínica. Seus escritos podem ser ligados a um grupo mais jovem de cirurgióes ginecológicos, uma coorte que está em marcante contraste com a geração de ginecologistas cujas carreiras abarcaram os primórdios da especialidade na década de 1850 e atingiram seu auge em 1880. Esse grupo mais velho de pioneiros tinha conhecimento da patologia e de sua importância no diagnóstico e tratamento, mas quando se tratava de questões envolvendo a saúde feminina eles especulavam, não apenas sobre assuntos estritamente científicos, mas a respeito das obrigações sociais da maternidade, da necessidade de se preservar a pureza sexual feminina e da importância da incomensurabilidade entre os corpos femininos e masculinos. Homens como Thomas Addis Emmet (1828-1919), E.H. Clarke (1820-1877) e A.J.C. Skene (18371900) construíram o corpo feminino com deferência, elaborando um local seguro e subordinado para as mulheres no interior do lar.

Em marcante contraste com a mescla de linguagem moral $e$ científica característica dos primeiros trabalhos de Skene e Emmet, houve a publicação de um elaborado e definitivo volume editado por Howard E. Kelly e Charles P. Noble, dois cirurgiões ginecológicos, em meados de carreira na virada do século XIX para o XX, que ajudaram a refinar e solidificar os avanços da especialidade no início de suas carreiras e que, gradualmente, tornaram-se figuras dominantes após 1890. Seu livro-texto, Gynecology and Abdominal Surgery, publicado em 1907, amplia as transformações iniciadas nas décadas anteriores. Evidentemente, técnica e diagnóstico fizeram grandes avanços. Porém, o mais instrutivo sobre o volume é o fato de que ele é completamente destituído da teorização filosófica própria à maioria dos textos de ginecologia de apenas duas décadas antes. O próprio Skene contribuiu com um ensaio sobre "ovariectomia" $e$, embora sua morte anterior à publicação do trabalho evoque uma espécie de passagem simbólica, mesmo a sua linguagem havia mudado. Seu capítulo, como os vinte e quatro demais, 
De "corpos" a "pessoas"

incluindo dois redigidos por médicas, concentra-se apenas em dados científicos e técnica cirúrgica. ${ }^{15}$

O amadurecimento da cirurgia ginecológica também significou a possibilidade de os cirurgiões oferecerem reais chances de cura a suas pacientes. As técnicas certamente permaneceram arriscadas, e nos anos de 1890 as taxas de mortalidade para tais operações ainda estavam em aproximadamente $15 \%$ (dos 66\% na década de 1860). Mas dadas as novas opções terapêuticas, os médicos necessitavam de um novo tipo de aquiescência das pacientes, propensa a incluir maior negociação e comunicação. Isso era particularmente necessário no caso de tais procedimentos invasivos e arriscados, embora não seja evidente que todos os cirurgiões tenham considerado esses novos imperativos com entusiasmo. Desse modo, o testemunho médico no processo por difamação revela uma ampla gama de opiniões sobre a questão do consentimento informado. Quanta informação os médicos deveriam dar antes da cirurgia?

Dentre suas várias alegações, o Eagle acusou Dixon Jones de má comunicação com os pacientes. Embora os testemunhos no julgamento não tenham sido conclusivos por razões óbvias, duas testemunhas chave em sua defesa, Gill Wylie e Abel M. Phelps, fizeram comentários sinceros. Suas observações contrastavam de forma evidente com as dos outros médicos que apoiaram a acusação do jornal de que Dixon Jones não explicava adequadamente suas decisões terapêuticas. No início do julgamento, por exemplo, A.J.C. Skene insistiu que os efeitos da cirurgia deveriam ser compreendidos por "todos os pacientes, exceto crianças e pessoas insanas". Ele próprio fora "particularmente cuidadoso em se fazer compreender por uma mulher ignorante". Muitos outros expressaram desconforto com a atitude ocasionalmente autoritária de Dixon Jones em relação aos maridos, e Skene observou que "ele não pensava que se pudesse

${ }^{15}$ Kelly, Howard e Noble, Charles P. (eds.) Gynecology and Abdominal Surgery. Philadelphia, W. B. Saunders, 1907. 
encontrar um cirurgião que operasse uma mulher contra a objeção do marido". Phelps, por outro lado, admitiu que raramente discutia procedimentos com "mulheres extremamente nervosas, incapazes de compreender uma explicação científica". Também não era comum que ele "explicasse de antemão os procedimentos para pacientes ignorantes" pois "elas poderiam fugir da mesa de operações" se lhes fosse dito o que aconteceria. Gill Wylie concordou.

O risco de laparotomias se tornou agora tão insignificante [ele declarou] que se faz muito menos cerimônia do que antes quanto a obter consentimento, assegurar assistentes $e$ coisas semelhantes. ${ }^{16}$

Embora tais observações nos façam lembrar que o entendimento atual do consentimento informado inexistia naquele período, a discussão sugere que os cirurgiões estavam entre os primeiros especialistas a debater e eventualmente recomendar a explicação e a comunicação cuidadosa talvez, em parte, por estarem mais sujeitos do que médicos em geral a serem processados por má conduta profissional. ${ }^{17}$

Há outras razões para os cirurgiões terem sido encorajados a falar francamente com as pacientes. Suas teorias de causalidade das doenças foram rapidamente se orientando para o local e o específico, em contraste com as abordagens sistêmicas e holísticas do clínico geral. É possível especular que eles tenham em pouco tempo aprendido a explicar que a dor e o desconforto eram causados pela infecção limitada de órgãos específicos, mais do

\footnotetext{
${ }^{16}$ Para uma discussão mais ampla do papel do consentimento informado e sua função no julgamento, ver MoRANTZ-SANCHEZ, R. Conduct Unbecoming... Op. cit., pp.187-188.

${ }^{17}$ Ver, particularmente, MoHR, James. Doctors and the Law. New York, Oxford University Press, 1993; DE VILLE, Kenneth. Medical Malpractice in Nineteenth Century America. New York, NYU Press, 1990, e Morantz-SANCHEZ, R. Conduct Unbecoming... Op. cit., pp.197-203.
} 
De "corpos" a "pessoas"

que pelo status biológico e teleológico de uma feminilidade, e que tais órgãos podiam ser removidos, com resultados positivos. A capacidade de gerar crianças poderia ser igualmente prejudicada, mas mesmo a discussão dessa eventualidade possibilitava que médico e paciente negociassem de forma inteligente sobre as vantagens do bem-estar diante da maternidade. Finalmente, porque no último terço do século XIX os ginecologistas ainda não haviam concordado quanto à eficácia da cirurgia no tratamento de doenças femininas, as pacientes eram compelidas a se tornarem agentes ativas na escolha de um médico; de fato, suas escolhas freqüentemente se voltavam para o médico que estivesse disposto a oferecer uma proposta terapêutica que fosse mais do seu agrado.

Nós podemos perceber algumas dessas mudanças no agenciamento feminino através da análise da fala das pacientes de Mary Dixon Jones sobre a adequação da comunicação com elas. Eu já observei que o testemunho no julgamento é contraditório. Por exemplo, Mary Webster alegou não ter sido bem informada sobre a natureza da cirurgia que sofreu, e tomou conhecimento a seu respeito através de outra paciente. Margaret Fisher testemunhou nunca ter autorizado sua operação, $e$ talvez não o tivesse feito se soubesse que isso a deixaria incapaz de ter filhos. ${ }^{18}$ No entanto, outras estavam bastante satisfeitas com as informações recebidas, e sentiam claramente que a decisão pela cirurgia fora feita em conjunto. A médica contou a Mary Huck que o tumor a ser removido era do "tamanho de uma laranja"; Clara Hartisch explicou que seus dois tumores cheios de pus eram do tamanho de um ovo de ganso. "A Dra. Jones removeu esses tumores e me curou completamente. Ela foi muito boa para mim, como ela era com todas as pacientes". John Bruggeman, cuja esposa finalmente se submeteu à cirurgia, admitiu não poder se lembrar dos detalhes da primeira consulta com Dixon Jones porque "minha mulher foi quem falou o tempo todo". Talvez a

${ }^{18}$ Eagle. 10 de fevereiro de 1892. 
mais eloqüente de todas tenha sido Mina Emmerich, que testemunhou que quando Dixon Jones a advertiu de que a cirurgia poderia não salvá-la, ela respondeu que queria qualquer coisa que a aliviasse, "viva ou morta". ${ }^{19}$

$\mathrm{O}$ que esses relatos revelam sobre o tipo de relação que Dixon Jones mantinha com suas pacientes é menos importante para nossos objetivos do que o fato de que as informações fornecidas durante a consulta pelos médicos eram valorizadas positivamente por todas as mulheres que testemunharam no julgamento. Médicos que serviram de testemunha discordavam sobre a quantidade de informação que deveria ser transmitida assim como o fazem ainda hoje - mas o tom da discussão no tribunal indica enfaticamente que os pacientes esperavam que um padrão mínimo de negociação $e$ obtenção de informação ocorresse durante a consulta. Muitos médicos disseram que não eram a favor de discussões tão francas, mas mesmo os mais relutantes reconheciam sua utilidade por impedir processos por má conduta profissional. Os artigos em periódicos médicos contemporâneos ecoam esses debates do tribunal. ${ }^{20}$

Estes relatos evidenciam também as relações de poder entre esses médicos e suas pacientes. Na literatura sobre médicos do sexo masculino e suas pacientes no século XIX há freqüentemente o pressuposto implícito de que os maridos, membros da família ou amigos eram responsáveis por chamar ou levar as mulheres doentes ao médico. O perspicaz estudo de Carroll Smith Rosenberg sobre a histeria, por exemplo, nos apresenta a imagem de uma mulher paralisada em meio à família, presa à sua cama, forçando assim os demais membros da família a assumirem o seu papel de esposa, mãe ou filha. "Consternação e preocupação pesavam sobre os ombros do marido", somos informados. "Seu lar subitamente se tornou um hospital, e ele, um enfermeiro".

${ }^{19}$ Citizen, 10 de junho de 1889; Eagle, 12 de fevereiro de 1892; Citizen, 10 de junho de 1889; Eagle, 24 de fevereiro de 1892.

${ }^{20}$ Morantz-SANCHEZ, R. Conduct Unbecoming... Op. cit., p.272. 
De "corpos" a "pessoas"

Presumidamente era o marido que convocava o médico à cabeceira da cama da paciente. ${ }^{21}$ Em Fasting Girls, de Joan Brumberg, os pais, com mais freqüência a mãe, procuram conselho e tratamento médico para filhas recalcitrantes. ${ }^{22}$ Por fim, a exploração de Mary Poovey do "corpo feminino silenciado", e sua relação com as lutas profissionais na Inglaterra em meados do século, representa as pacientes como passivas. Os médicos "adentram" a sala de parto; eles "assistem" a histérica. A maneira exata como elas chegam até ali permanece um mistério. O que parece estar faltando no relato de Poovey é a possibilidade de que os médicos de fato possam ter sido convocados a prestar tratamento pelas próprias pacientes. ${ }^{23}$

O grande número de depoimentos concedidos, combinados com as reportagens de jornal e os próprios registros do caso de Dixon Jones, fornecem algumas informações fascinantes sobre as queixas de doença e seus tratamentos. Ouvimos a respeito da natureza dos sintomas físicos das pacientes, o que sentiam em relação a seus corpos e suas doenças, suas expectativas em relação aos médicos, padrões de cuidado, e como Dixon Jones e vários de seus colegas masculinos se apresentavam a seus clientes. Aprendemos que as mulheres de classe média não eram dependentes de seus médicos para obter informação sobre seus próprios corpos. Aparentemente, elas se mantinham cuidadosamente em dia com os progressos da ginecologia $e$ estavam familiarizadas com as possibilidades da intervenção cirúrgica. No Brooklyn, o material é surpreendentemente abundante. Os corpos de pacientes mulheres nessa cidade estavam longe de serem silenciados; ao contrário, as doentes atentavam para os sinais e sintomas físicos e monitoravam suas

${ }^{21}$ Rosenberg, Carroll Smith. The Hysterical Woman: Sex Roles and Role Conflict in Nineteenth-Century America. Social Research (39), Winter 1972, p.208.

22 BRumberG, Joan. Fasting Girls: The Emergence of Anorexia Nervosa as a Modern Disease. Cambridge, Harvard University Press, 1988, pp.140-163.

${ }^{23}$ PoOvey, M. "Scenes of an Indelicate Character"... Op.cit., pp.148, 152, 153. 
experiências de doença com uma firme determinação e de modo assertivo. Elas procuravam o conselho de numerosos profissionais para suavizar sua dor persistente e seu desconforto crônico. Caso considerassem o tratamento ineficaz, buscavam outro, não demonstrando lealdade duradoura a um médico específico ou a uma terapia particular. ${ }^{24}$

As pacientes tinham razão em procurar outra opinião, pois não existia consenso em como tratar doenças ginecológicas, mesmo entre os especialistas no campo. A maior parte das mulheres procurava mitigar os sintomas que as limitavam $e$ restaurar a funcionalidade $e$ a autonomia de suas vidas. $\mathrm{O}$

${ }^{24}$ Morantz-SAnchez, R. Negotiating Power... Op. cit. Nancy Theriot argumenta que as filhas que amadureciam nos anos de 1880 estavam menos dispostas do que a geração de suas mães a se conformar com a dor e o sofrimento que se esperava que acompanhassem o ciclo de vida reprodutivo feminino. Ver THERIOT, N. Mothers and Daughter... Op.cit., pp.80-82. Suas descobertas reforçam o argumento de Edward Shorter de que, em contraste com o paciente tradicional, que possuía um elevado limiar de dor e maior tolerância à doença crônica, o paciente moderno apresentava maior sensibilidade às vicissitudes do corpo, e procurava o conselho de especialistas mais rapidamente. Ver SHORTER, Edward. Bedside Manners: The Troubled History of Doctors and Patients. New York, Simon and Schuster, 1985, p.61. O fato de as mulheres mudarem repetidamente de médicos não surpreenderia os modernos sociólogos da medicina, que descobriram que, embora as mulheres possam parecer passivas no consultório médico, elas assumem um papel mais ativo na administração de sua saúde fora do ambiente clínico formal. As mulheres ainda tendem, mais do que os homens, a trocar de médico. Alguns estudiosos argumentam que elas também se voltam mais prontamente a "métodos de cura não-convencionais". Em resumo, escreve Alexandra Dundas Todd sobre as atitudes femininas atuais, "As mulheres usam a assistência médica mais do que os homens, talvez devido a uma socialização mais voltada para o auxílio e à sua necessidade de serviços de saúde para o cuidado reprodutivo, tanto quanto por doença. A literatura (...) ilustra que ao procurar tal assistência, as mulheres relatam muitas insatisfações. Não há evidência, entretanto, de que estas insatisfações sejam comunicadas aos médicos. De fato, as queixas das mulheres, em geral, parecem assumir a forma da rebelião silenciosa, tal como a não adesão e a troca de especialistas, mais do que o confronto direto". Ver TODD, Alexandra Dundas. Intimate Adversaries: Cultural Conflict Between Doctors \& Women Patients. Philadelphia, University of Pennsylvania Press, 1989, pp.40-41. 
De "corpos" a "pessoas"

testemunho no julgamento de Dixon Jones revela que, em alguns casos, mulheres consultaram mais de 20 profissionais antes de chegarem à porta de seu consultório. Os ditames da cultura de consumo eram exercidos por muitas em sua busca por assistência médica eficaz. Eram, afinal, primordialmente mulheres que compunham a clientela das lojas de departamento nesse período, $e$ o ato de fazer compras estava sendo codificado como feminino ao fim do século XIX. As mulheres estavam se tornando os principais agentes das compras para suas famílias, o que as ajudou a se conceberem como administradoras responsáveis pelo lar, e elas tinham orgulho de sua habilidade de escolher o que comprar. Por que as mesmas regras de consumo não deveriam se aplicar à assistência médica? Havia um vívido mercado médico no Brooklyn e na cidade de Nova Iorque no final do século XIX, e a ginecologia como um negócio estava aparentemente sofrendo um boom. $^{25}$

A Sra. Alfred Strome, por exemplo, disse em 1889 tanto ao Eagle quanto ao Citizen que ela esteve doente por 14 anos antes de se consultar com Dixon Jones. Ela procurou a opinião do Dr. Westbook, que a advertiu contra a cirurgia dizendo que iria matála.

Não satisfeita com isso [Strome lembrava] eu fui a vários outros médicos na cidade e fora dela, mas com o mesmo resultado negativo. (...) Tendo abandonado toda a esperança de cura completa e permanente,

Ela foi finalmente convencida por uma amiga a visitar Dixon Jones. A doutora removeu os tumores abdominais de Strome e a curou. ${ }^{26}$ Outra paciente tratada pela médica em 1884, sobre quem

${ }^{25}$ Sobre mulheres e compras, ver ABELSON, Elaine. When Ladies Go A-Thieving: Middle-Class Shoplifters in the Victorian Department Store. New York, Oxford University Press, 1989; LEACH, William. Land of Desire: Merchants, Power, and the Rise of a New American Culture. New York, Vintage Press, 1993.

${ }^{26}$ Eagle, 11, 14 de maio de 1889; Citizen, 20 de junho de 1889. 
ela publicou um relato de caso, tentou vinte e um médicos antes do contato com a médica, e uma terceira, cujo desconforto era tão agudo que tentara suicidar-se, confessou ter apelado a "trinta médicos diferentes". ${ }^{27}$

Alguns dos melhores especialistas da cidade de Nova Iorque e do Brooklyn haviam examinado a Sra. A. E. Scholtz: "Dr. Skene, Dr. Thomas, Dr. Fowler e outros". Nenhum deles sugeriu a cirurgia. Suas amigas a instigaram a procurar Dixon Jones, que a operou de um tumor com sucesso. ${ }^{28}$ Victoria James, uma paciente afro-americana, confessou ter visto "seis médicos antes de ir ao... hospital [de Dixon Jones] e nenhum deles me fez bem algum". ${ }^{29}$ Mary Vibert convocou 14 médicos à sua casa no mesmo número de meses. ${ }^{30}$ Quando se indagou a Mary Gearon, no banco de testemunhas, a respeito do que Dixon Jones lhe dissera quanto à natureza de sua cirurgia, ela respondeu, "Bem, não consigo me lembrar, fui a tantos médicos desde então". ${ }^{31}$ Do mesmo modo, a Sra. Frances Stroble foi ao dispensário de Dixon Jones na Madison Avenue em 1887, após permanecer doente por 20 anos. "Ela foi a todos os médicos que pôde", o Eagle a retratou dizendo, "mas eles não resolveram o seu problema". ${ }^{32}$ Finalmente, a Sra.

${ }^{27}$ DIXON JONES, Mary. Another Hitherto Undescribed Disease of the Ovaries. Anomalous Menstrual Bodies. New York Medical Journal (51), 10 de maio de 1890, pp.542; e Diagnosis and Some of the Clinical Aspects of Gyroma and Endothelioma of the Ovary. Buffalo Medical and Surgical Journal (32), Novembro de 1892, p.209.

${ }^{28}$ Eagle, 13 de fevereiro de 1892. Ver também 19 de maio de 1889. Embora partes da história de Scholtz sejam contraditórias, sua incessante busca pelo médico perfeito não o é.

${ }^{29}$ Citizen, 24 de fevereiro de 1892.

${ }^{30}$ Eagle, 26 de fevereiro de 1892.

${ }^{31}$ ID., 9 de fevereiro de 1892.

32 ID., 25 de fevereiro de 1892. 
De "corpos" a "pessoas"

Mina Emerich, que tinha dores em seu baixo-abdômen, havia visto pelo menos cinco profissionais diferentes entre 1883 e $1887 .{ }^{33}$

A publicidade e o espetáculo ao redor do julgamento iluminaram essas redes informais de mulheres que atuavam na administração de sua própria assistência à saúde. Considerar sua atuação como norma sem dúvida encorajou outras mulheres, principalmente aquelas tantas que manifestaram um grande interesse pelo evento. A partir dos dias de abertura do julgamento, os jornais ressaltaram o comparecimento sem precedentes de mulheres ao tribunal. "O caso Jones começou a exercer uma fascinação mórbida sobre as mulheres da cidade", observou o Eagle em 12 de fevereiro de 1892.

A maior parte delas esteve presente a quase todas as sessões do tribunal desde que o julgamento do caso começou, e ontem à tarde, a parte de trás do tribunal estava repleta de faces femininas alertas, se esticando ansiosamente para cima e adiante conforme as mulheres no banco de testemunha contavam a penosa história de seus sofrimentos.

O jornal argumentava que era "apenas natural" que houvesse uma maior proporção de mulheres na platéia do que o habitual nas "multidões de tribunal", notando que o testemunho apelava "à compaixão das mulheres com força peculiar".${ }^{34} \mathrm{Em}$

${ }^{33}$ Citizen, 10 de junho de 1889. Ver também os casos seguintes: Sra. Bruggeman, Eagle, 7 de maio de 1889, Citizen, 12 de fevereiro de 1892; Sra. Hulten, Eagle, 11 de maio de 1889; Sra. Fisher, Eagle, 14 de maio de 1889, 10 de fevereiro de 1892, Citizen, 10 de fevereiro de 1892; Sra. Nash, Eagle, 17 de maio de 1889, Eagle, 12 de fevereiro de 1892; Srta. Olsen, Eagle, 14 de junho de 1889; Ida Hunt, Eagle, 31 de maio de 1889 e 17 de fevereiro de 1892; Sra. Rettinger, Eagle, 13 e 15 de fevereiro de 1892; Sra. Clara Hartisch, Citizen, 10 de junho de 1889; Margaret Walsh, Citizen, 10 de junho de 1889; Srta. Hattie Coulson, Citizen, 20 de junho de 1889; Sra. Maggy Laklbreunar, Eagle, 24 de fevereiro de 1892; Charlotte Mason, Eagle, 25 de fevereiro de 1892. Os registros do caso de Dixon Jones contam exatamente a mesma história.

${ }^{34}$ Eagle, 12 de fevereiro de 1892. 
sua maioria, era uma multidão de classe média "bem vestida", "refinada" e "inteligente". ${ }^{35}$ Por que estavam lá?

Argumento que a platéia feminina autorizada por esse evento, somada à transformação do encontro médico-paciente possibilitada pela cirurgia ginecológica, confirmou as novas percepções das mulheres sobre seus próprios corpos $e$ lhes ofereceu um fórum efetivo tanto para o compartilhamento vicário de experiências quanto para o acúmulo de informação. Para as mulheres de classe média $e$ as pobres imigrantes que vinham ao tribunal para falar em público sobre a penosa experiência da doença, o julgamento promoveu uma via pública incomum para veicular as decepções e queixas sobre a condição feminina, ou mesmo contar pequenos triunfos, num contexto que lhes oferecia uma platéia compassiva e cativa. A cirurgia ginecológica assumiu particular urgência no final do século XIX, conforme os avanços na técnica médica transformaram as "vontades" das mulheres, nomeadamente seu desejo por boa saúde, em "necessidades", no direito de exigí-la de seus médicos. O julgamento forneceu uma rara oportunidade para que tal discussão tivesse espaço fora dos periódicos médicos, aos quais as mulheres leigas tinham pouco acesso. Nesse tribunal, o corpo feminino e suas partes podiam ser colocados à apreciação pública sem incidentes. Ele poderia ser cientificamente discutido por especialistas médicos enquanto uma platéia decorosa observava. Esse fato, por si só, sugere que por volta do encerramento da Era Dourada, o confinamento das mulheres vitorianas à casta e modesta privacidade da esfera doméstica estava rapidamente chegando ao fim. ${ }^{36}$

\footnotetext{
${ }^{35}$ ID., 3 e 4 de fevereiro de 1892.

${ }^{36}$ Ao lado dos insights de Theriot sobre mães e filhas, é instrutivo o maravilhoso estudo de Jane Hunter que mapeia, a partir dos anos de 1880, o papel de escolas públicas de co-educação na produção de jovens mulheres com diferentes expectativas e concepções mais ambiciosas sobre as possibilidades femininas no mundo. Este é o tipo de jovem mulher que tendia a se apossar mais prontamente de seu próprio corpo. Ver HUNTER, Jane H. How Young Ladies Became Girls:
} 
De "corpos" a "pessoas"

Julgamentos públicos populares contam ao menos duas histórias ao mesmo tempo. A primeira pertence, sobretudo, aos personagens envolvidos. A segunda, talvez ainda mais cativante e instrutiva do que a primeira, espelha o campo mais amplo da política e da cultura em que o julgamento ocorre. Argumentei de início que o caso de Mary Dixon Jones nunca foi simplesmente a história de uma excêntrica e notável médica do século XIX. Eu espero ter demonstrado a relevância desse evento e de outros similares para compor uma compreensão mais clara e nuançada sobre a transformação histórica e social.

The Victorian Origins of American Girlhood. New Haven, Yale University Press, 2002. 